\title{
A LINGUAGEM DE PROGRAMAÇÃO SCRATCH E O ENSINO DE FUNÇÕES: UMA POSSIBILIDADE
}

\author{
Sandra Mara Oselame Riboldi ${ }^{1}$, Janice Teresinha Reichert ${ }^{2}$, \\ ${ }^{1}$ Acadêmica do Mestrado Profissional em Matemática em Rede Nacional - Universidade \\ Federal da Fronteira Sul (UFFS) \\ ${ }^{2}$ Professora Doutora da Universidade Federal da Fronteira Sul (UFFS) \\ Chapecó - SC - Brazil \\ sandrariboldi@gmail.com, janice.reichert@uffs.edu.br
}

\begin{abstract}
This paper describes a quasi-experimental study that aimed to investigate the possible contributions that the Scratch programming language can bring to the introduction of the concept of functions in a 9th grade class of a state public school in Santa Catarina. The action research was conducted from March to May 2019 and lasted 20 meetings, totaling 30 hours, with the participation of 26 students. Students were evaluated before and after the development of the activities, to verify the previous knowledge and evolution in learning, with open and closed questions related to computational thinking, use of technologies and knowledge about the content of functions. The results were analyzed in a quali-quantitative way and point to a significant improvement in learning and interest in mathematics.
\end{abstract}

Resumo. Este trabalho descreve um estudo quase experimental que teve como objetivo investigar as possíveis contribuições que a linguagem de programação Scratch pode trazer na introdução do conceito de funções, em uma turma de $9^{\circ}$ ano de uma escola pública estadual de Santa Catarina. A pesquisa-ação foi realizada durante os meses de março até maio de 2019 e teve duração de 20 encontros, num total de 30 horas, com a participação de 26 estudantes. Os alunos foram avaliados antes e após o desenvolvimento das atividades, para verificação dos conhecimentos prévios e evolução na aprendizagem, com questões abertas e fechadas, relacionadas ao pensamento computacional, uso de tecnologias e conhecimentos sobre o conteúdo de funções. Os resultados foram analisados de forma quali-quantitativa $e$ apontam para uma significativa melhora na aprendizagem e no interesse pela Matemática.

Palavras-Chave: Ensino Fundamental. Funções. Pensamento Computacional. Scratch.

\section{Introdução}

No Brasil, estamos passando por um momento de reformulação do currículo da Educação Básica. Recentemente foi aprovada a Base Nacional Comum Curricular (BNCC) para o Ensino Fundamental e Médio, onde a ideia do pensamento computacional, principalmente na área da Matemática, está fortemente incluída [Brasil 
2017]. Embora a concepção da BNCC, seja algo recente, não podemos nos omitir, pois, enquanto educadores é nosso dever estar constantemente atualizados e dispostos a conhecer o novo. Nas diversas etapas da aprendizagem, a linguagem de programação Scratch pode ser utilizada para desenvolver o pensamento computacional. Em pesquisas já realizadas com o seu uso, [Martins 2012], o retratou como potencializador do pensamento criativo e fez uma reflexão sobre vários aspectos de como utilizar o computador em sala, em prol da construção de conhecimento. Por outro lado, [Neto 2013] propôs o uso do Scratch na introdução de uma disciplina de lógica da programação em um curso técnico em informática como fator motivacional. [Pazinato 2014] relata a sua utilização em uma oficina de formação continuada para professores da Educação Básica, como uma ferramenta auxiliar no processo de aprendizagem de conceitos matemáticos. Em seu trabalho, [Miotto 02014] realizou uma pesquisa com alunos do $9^{\circ}$ ano de uma escola no estado do Paraná, no qual propõe algumas atividades de funções realizadas com auxílio do software Scratch e com a metodologia de ensino da Modelagem Matemática

Em todos os estudos citados, os sujeitos pesquisados obtinham informações para realizar uma determinada tarefa, ou solucionar um problema dado, onde suas habilidades eram testadas e seu raciocínio para a execução da tarefa analisado.

Observa-se que, embora existam publicações na área de Matemática sobre a utilização do Scratch, não encontramos trabalhos relacionados a ideia do pensamento computacional atrelado à BNCC. A publicação de [Miotto 2014] relata atividades de aprendizagem relativas ao conceito de funções, porém o enfoque está na Modelagem Matemática de algumas situações-problemas e, o Scratch é utilizado como ferramenta para inserir figuras da internet, criar textos explicativos para a solução das questões. Desta forma, o Scratch serviu para ilustrar as respostas apresentadas, não explorando os comandos de programação na construção do conhecimento sobre o tema funções e nem para a realização de gráficos.

No trabalho, aqui apresentado, o objetivo principal está no uso do Scratch para desenvolver o pensamento computacional atrelado à introdução do conceito de funções, trabalhando lei de formação, domínio e imagem, valor numérico, gráficos de funções e explorando os comandos de programação, sendo este o diferencial assumido nesta pesquisa. Nessa perspectiva, realizou-se este estudo, sendo o artigo organizado da seguinte forma: na seção 2 apresentamos uma descrição dos métodos de pesquisa utilizados e a sequência de atividades desenvolvidas. A seção 3 relata os resultados e discussões e a seção 4 as conclusões gerais. Por último são apresentadas as referências bibliográficas.

\section{Métodos}

Esta pesquisa foi realizada com uma turma do $9^{\circ}$ ano do Ensino Fundamental, composta de 26 alunos, de uma escola da rede pública estadual de Santa Catarina. Sendo, 12 meninos e 14 meninas com idades variando de 13 a 18 anos. Ocorreu durante os meses de março até maio de 2019 e teve duração de 20 encontros, num total de 30 horas.

As atividades realizadas com os educandos seguiram um roteiro planejado anteriormente pelo pesquisador e adaptadas posteriormente quando necessário. Aplicouse um questionário inicial, chamado de pré-teste, com 35 questões. Sendo 20 relacionadas ao uso de tecnologias, 10 específicas sobre pensamento computacional e 05 questões sobre o conteúdo de funções. 
As questões do teste de pensamento computacional, tiveram como referências os trabalhos de [Román-Gonzáles 2015] e [Backmann 2017] e duas foram relacionadas à descrição de passos para executar uma atividade específica, como por exemplo, "descrever detalhadamente o trajeto de sua casa até a Escola". Após o desenvolvimento das atividades os estudantes formam avaliados por um pós-teste, contendo 6 questões. Destas, 3 foram novamente extraídas do teste de pensamento computacional e 3 foram reformuladas do questionário inicial.

Feita a sondagem sobre conhecimentos prévios que os alunos possuíam, mesmo que de forma intuitiva, foram definidas as atividades a serem trabalhadas. Paralelamente às ideias de [Ausubel 1982], foram usados momentos em que a aula teve um direcionamento mais tradicional e outros em que o processo ocorreu de forma mais dinâmica. Uma vez apresentada a ferramenta Scratch, os estudantes foram divididos em duplas e produziram suas criações de acordo com a sequência de atividades sugeridas. Para alcançar os objetivos propostos, foram executadas as seguintes etapas:

\section{Quadro 1. Planejamento inicial}

\begin{tabular}{|c|c|}
\hline Encontro 1 ( 2 aulas) & $\begin{array}{l}\text { Apresentação e orientações relativas ao desenvolvimento de } \\
\text { cada etapa do projeto. Aplicação de questionário a fim de } \\
\text { coletar informações relevantes à pesquisa. }\end{array}$ \\
\hline Encontro 2 (1 aula) & $\begin{array}{l}\text { Introdução do conceito de funções fazendo uso do texto: "A } \\
\text { função das funções", [Gonçalves 2016]. }\end{array}$ \\
\hline Encontro 3 ( 3 aulas) & $\begin{array}{l}\text { Definir função matematicamente. Lei de formação fazendo } \\
\text { uso do jogo "Mestre e adivinho", [Smole 2007]. }\end{array}$ \\
\hline Encontro 4 ( 2 aulas) & Domínio e imagem de uma função afim. Atividades. \\
\hline Encontro 5 ( 2 aula) & As funções e suas aplicações. \\
\hline Encontro 6 ( 2 aulas) & $\begin{array}{l}\text { Apresentação da linguagem de programação Scratch: } \\
\text { comandos básicos. }\end{array}$ \\
\hline $\begin{array}{l}\text { Encontros } 7 \text { e } 8 \text { ( } 4 \\
\text { aulas) }\end{array}$ & $\begin{array}{l}\text { Construção de jogos e animações como exemplos para } \\
\text { aprenderem a manusear o Scratch. }\end{array}$ \\
\hline Encontro 9 (4 aulas) & $\begin{array}{l}\text { Explorar no Scratch a construção de gráficos de funções } \\
\text { afins e compreender inclinação da reta, } \\
\text { crescimento/decrescimento relacionado com os coeficientes } \\
\text { de uma função de afim. }\end{array}$ \\
\hline Encontro 10 (3 aulas) & $\begin{array}{l}\text { Revendo todo o conteúdo sobre funções explorados até este } \\
\text { encontro. }\end{array}$ \\
\hline Encontro 11 (2 aulas) & $\begin{array}{l}\text { Planejamento (em duplas) do "Projeto" sobre o assunto } \\
\text { funções, que farão utilizando o Scratch }\end{array}$ \\
\hline $\begin{array}{l}\text { Encontros } 12 \text { e } 13 \text { ( } 10 \\
\text { aulas) }\end{array}$ & Construção do "Projeto" no Scratch. \\
\hline Encontro 14 (2 aulas) & Apresentação do "Projeto" aos colegas \\
\hline Encontro 15 (2 aulas) & Avaliação escrita. \\
\hline Encontro 16 (1 aula) & Aplicação do Pós-teste \\
\hline
\end{tabular}

Fonte: Elaborado pelo próprio pesquisador. 
VIII Congresso Brasileiro de Informática na Educação (CBIE 2019)

Anais do XXV Workshop de Informática na Escola (WIE 2019)

Reportando-se novamente ao proposto no projeto e com o propósito de compreender como usar a ferramenta Scratch, construir projetos a partir das situaçõesproblemas e trabalhar lei de formação e representação gráfica, foram realizadas as seguintes intervenções:

Problema 1: Considere regiões retangulares nas quais a base, constante, mede $3 \mathrm{~cm}$ e a altura, variável, tem respectivamente $1 \mathrm{~cm}, 2 \mathrm{~cm}, 3 \mathrm{~cm}, 4 \mathrm{~cm}, \ldots . . x \mathrm{~cm}$. É possível estabelecer relações entre a área y e a altura $x$ desses retângulos? Objetivando levar os estudantes a perceber que a altura poderia variar formando desta forma uma função, foram orientados a desenvolverem três projetos no Scratch.

No Projeto A, considerou-se a construção de um retângulo de base 3 e altura 1 descrita no problema. Usaram equivalências para as medidas, sendo que 150 equivale a base 3 e proporcionalmente 50 equivale a altura 1, conforme podemos visualizar na Figura 1.

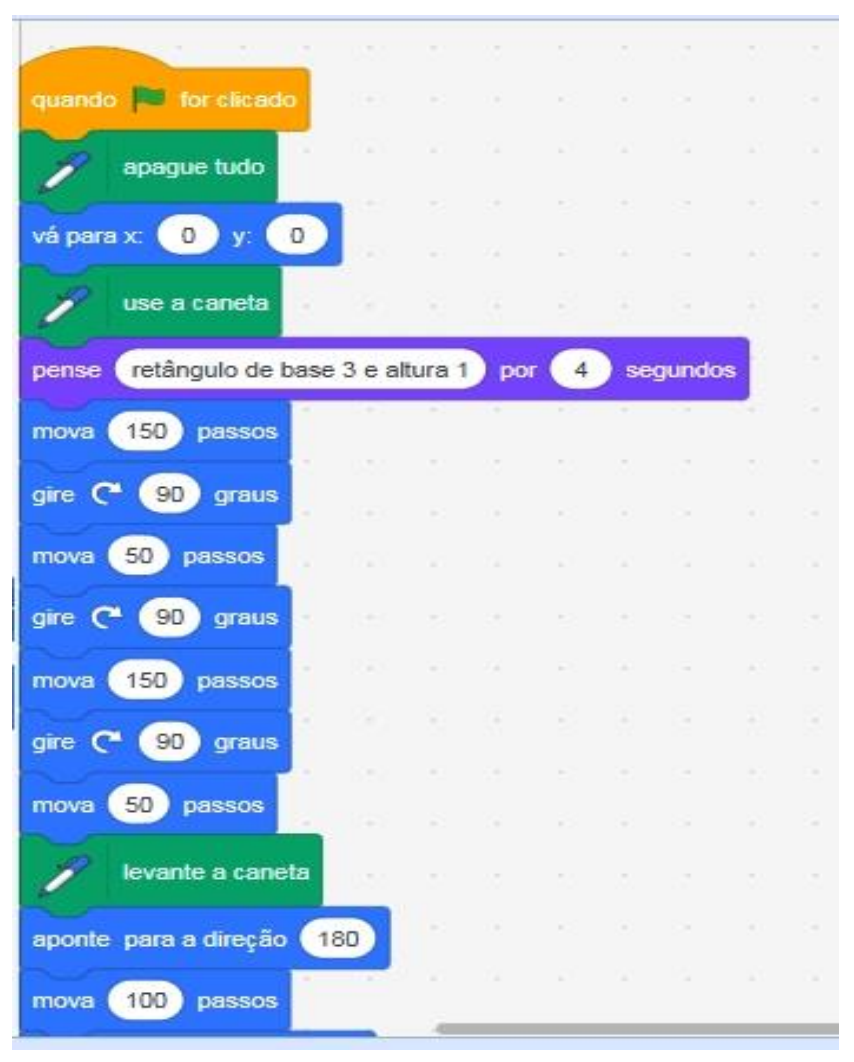

Figura 1: Construindo um retângulo

No projeto $\mathbf{B}$, exploramos a relação envolvida no perímetro destes retângulos caso variássemos sua altura e verificamos que a relação envolvida entre perímetro e altura é uma função na qual seu gráfico é uma reta crescente. Para isso construímos um gráfico relacionando o perímetro de uma região retangular de base $3 \mathrm{~cm}$ em função da medida da sua altura. Na Figura 2 podemos visualizar a atividade. 
VIII Congresso Brasileiro de Informática na Educação (CBIE 2019)

Anais do XXV Workshop de Informática na Escola (WIE 2019)

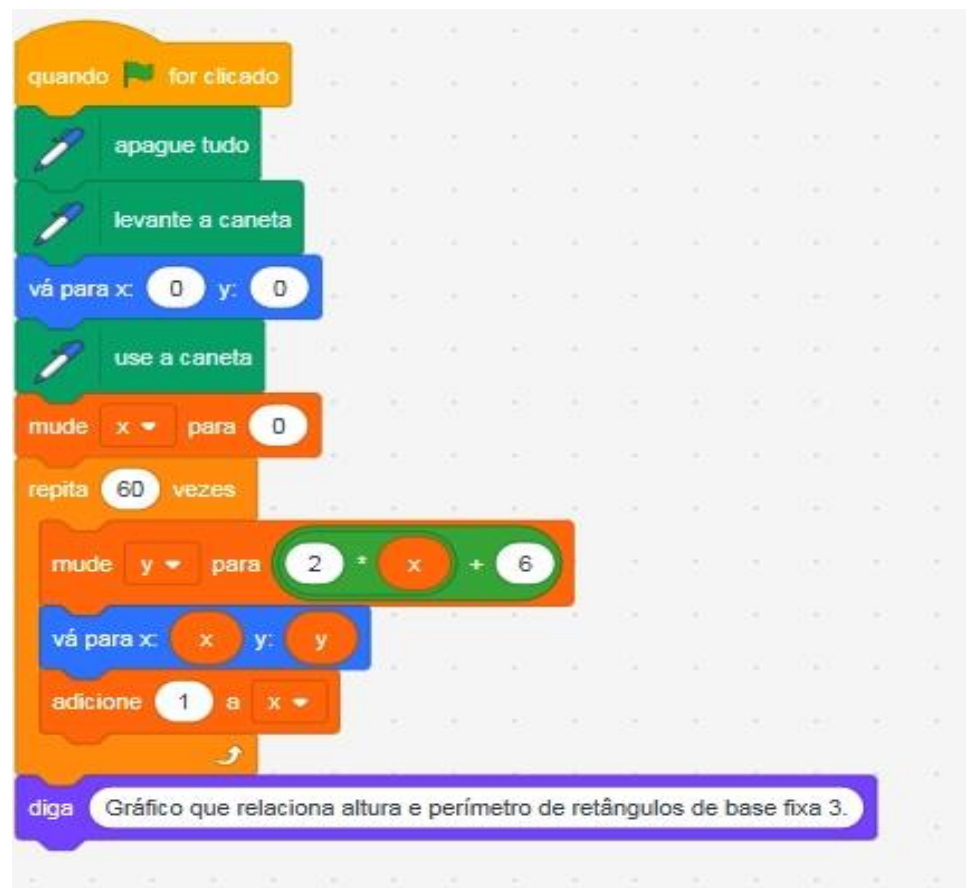

Figura 2: Gráfico do perímetro de um retângulo de base 3 e altura variável

Já no Projeto C, observamos o que acontece com a área desses retângulos, encontramos a relação envolvida e construímos um gráfico relacionando a área de uma região retangular de base $3 \mathrm{~cm}$ em função da medida da sua altura. $\mathrm{O}$ detalhamento da atividade pode ser visualizado na Figura 3.

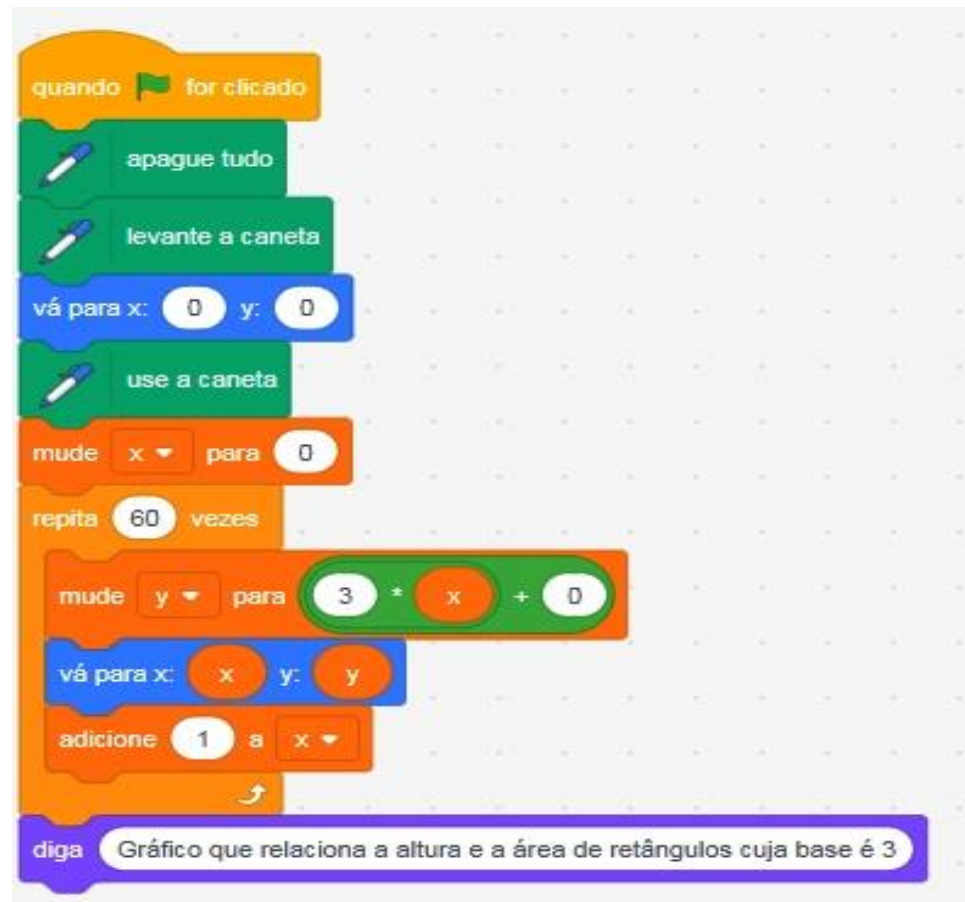

Figura 3: Gráfico da área de um retângulo de base 3 e altura variável

Problema 2: No posto de gasolina "Dos Maria”, o preço da gasolina custa por litro $R \$ 4,20$. Sabendo que o preço a pagar é função do número de litros, determine: 
VIII Congresso Brasileiro de Informática na Educação (CBIE 2019)

Anais do XXV Workshop de Informática na Escola (WIE 2019)

a) A função envolvida nesta situação;

b) o valor a pagar por 15 litros de gasolina;

c) quanto de gasolina foi comprado com $R \$ 42,00$;

d) construa o gráfico que relaciona o preço a pagar em função do número de litros de gasolina comprados.

O objetivo da atividade é relacionar todo o conteúdo estudado sobre funções e a linguagem de programação Scratch. No projeto D, criaram um jogo que responda o preço a ser pago da gasolina em função do número de litros comprados. Para isso executaram os seguintes comandos, descritos na Figura 4.

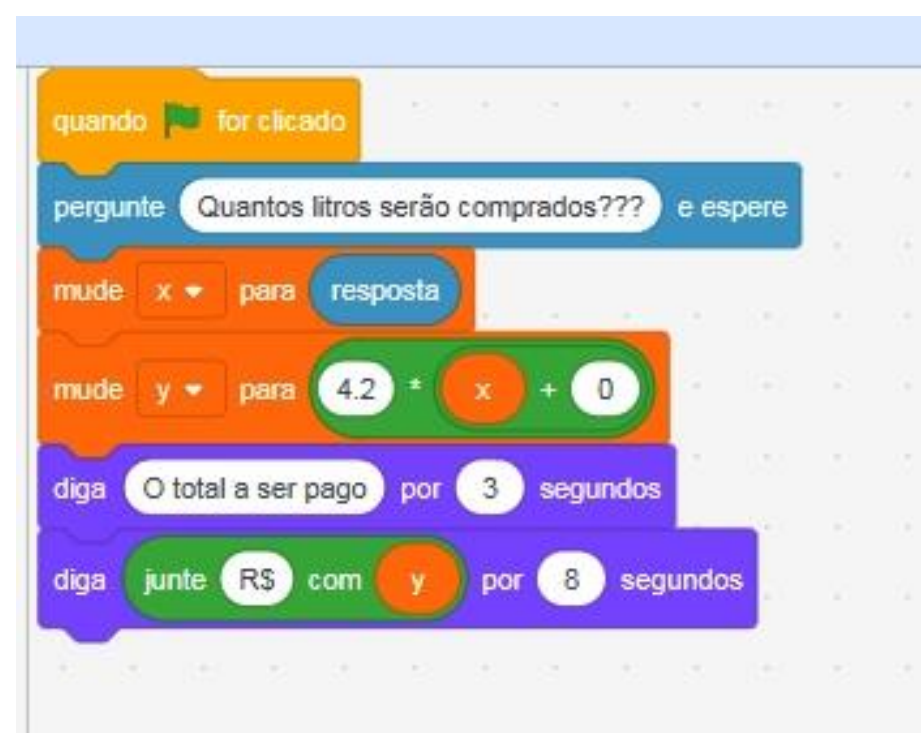

Figura 4: Jogo desenvolvido no projeto $D$

Levando em consideração o aprendizado do tema e a fim de explorar no Scratch a construção de gráficos de funções afins e compreender inclinação da reta, crescimento/decrescimento relacionado com os coeficientes da função, trabalhou-se com simulações baseadas nos projetos já construídos. Na Figura 5, apresentamos um exemplo de função afim, com inclinação 4,2 e termo independente 15. 


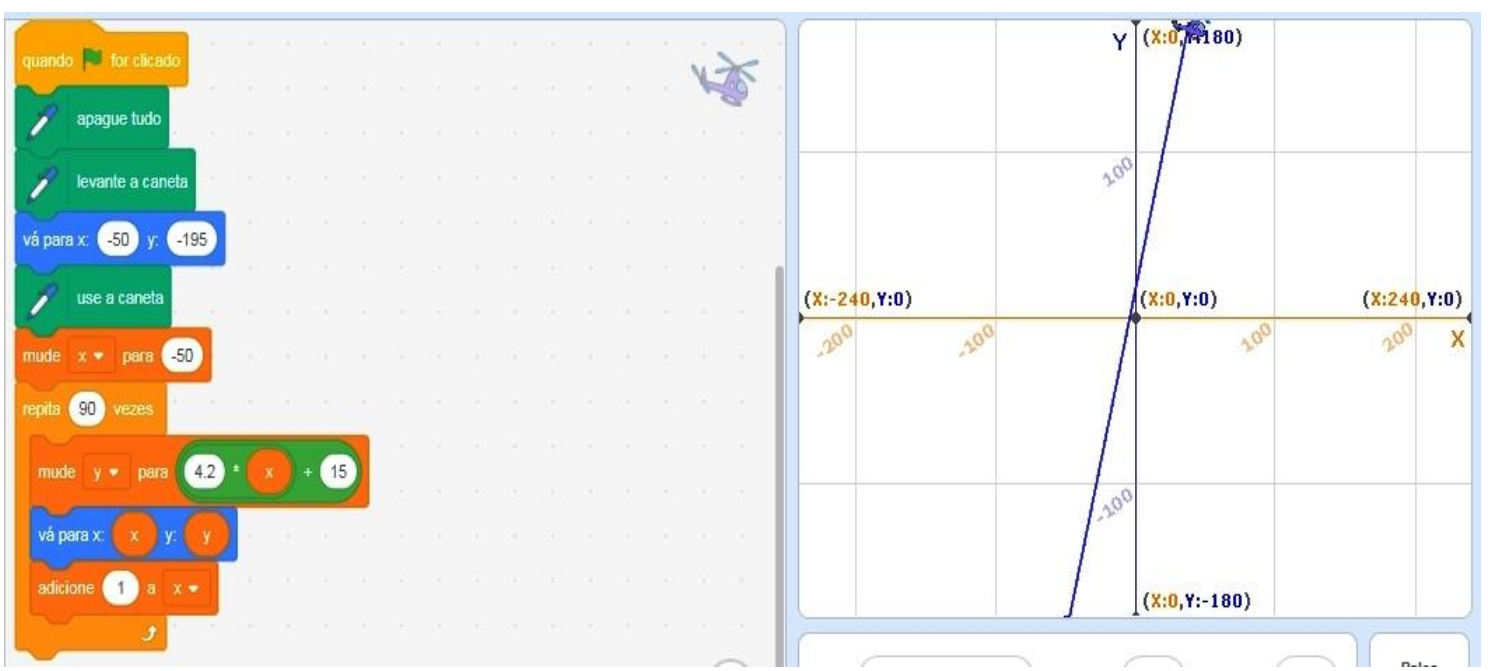

Figura 5: Função do 10 grau

Após a realização dos procedimentos acima e visando uma conjunção entre função afim com o pensamento computacional, os estudantes foram convidados a realizarem um projeto final, onde construíram um jogo relacionando o que havíamos abordado nos encontros anteriores, sendo 12 os projetos realizados.

\section{Resultados e Discussões}

Com base no pré-teste aplicado aos estudantes podemos observar que o nível de interesse pelo uso da tecnologia de maneira geral era de $100 \%$, sendo que sua utilização se baseava geralmente para pesquisas e leituras, jogos e acesso a redes sociais. Quando questionados sobre o conhecimento de alguma ferramenta de criação de jogos $80 \%$ disseram não conhecer nenhuma e o restante disse conhecer alguma, porém não especificar qual. Foi então sugerido a eles a ideia de criar jogos utilizando ferramentas computacionais e a maioria acreditou ser algo muito interessante e que daria certo. Todos os estudantes disseram não conhecer a linguagem de programação Scratch e 80\% nunca teve experiências com pensamento computacional.

Após aplicação das atividades propostas aplicamos um pós-teste e verificamos uma melhora significativa com relação ao tema proposto, os estudantes na sua maioria já conseguiram responder as questões referentes ao conteúdo e novamente foram questionados sobre o pensamento computacional, onde pudemos perceber uma ênfase maior em detalhes e motivação para responder as questões. A título de exemplo, detalharemos duas das questões realizadas no pós-teste e faremos um comparativo com as respostas apresentadas no pré-teste.

Questão 1: Descreva detalhadamente como você percorre o trajeto da sua casa até a escola. Você consegue descrever novamente esse trajeto com melhor riqueza de detalhes? Se sim, descreva. Observamos que $95 \%$ dos estudantes responderam que sim e conseguiram descrever de forma mais consistente e com maior riqueza de detalhes a essa pergunta, podemos perceber avanços nas respostas. As noções de quanto andar (em metros) e quanto girar (em graus) já se faz presente. Observe na Quadro abaixo um comparativo de três alunos, em suas respostas dadas. 
VIII Congresso Brasileiro de Informática na Educação (CBIE 2019)

Anais do XXV Workshop de Informática na Escola (WIE 2019)

Quadro 2. Comparativo da Questão 1

\begin{tabular}{|c|c|c|}
\hline Aluno & Resposta dada no pré-teste & Resposta dada no pós-teste \\
\hline A & $\begin{array}{l}\text { - saio de casa } \\
\text { - viro a esquerda } \\
\text { - vou ate um cruzamento } \\
\text { - vejo se não vem carros } \\
\text { - atravesso } \\
\text { - vou reto ate outro cruzamento } \\
\text { - faço o mesmo processo } \\
\text { - continuo ate chegar a escola }\end{array}$ & $\begin{array}{l}\text { - saio de casa em direção a rua } \\
\text { - viro } 90 \text { graus a esquerda } \\
\text { - chego na calçada } \\
\text { - ando } 100 \text { metros } \\
\text { - atravesso a rua } \\
\text { - ando mais } 100 \text { metros } \\
\text { - atravesso outra rua } \\
\text { - ando } 90 \text { metros } \\
\text { - viro } 90 \text { graus a esquerda } \\
\text { - entro na escola }\end{array}$ \\
\hline B & $\begin{array}{l}\text { - avance duas quadras } \\
\text { - vire a esquerda }\end{array}$ & $\begin{array}{l}\text { - desço duas quadras }(200 \mathrm{~m}) \\
\text { - viro para a esquerda } 90^{\circ} \\
\text { - ando } 50 \text { metros } \\
\text { - cheguei no portão da escola. }\end{array}$ \\
\hline $\mathrm{C}$ & $\begin{array}{l}\text { - segue reto } \\
\text { - vira à esquerda } \\
\text { - vira à direita } \\
\text { - segue reto }\end{array}$ & $\begin{array}{l}\text { - ando } 100 \text { metros } \\
\text { - viro a esquerda } \\
\text { - sigo reto } 100 \text { metros } \\
\text { - viro à direita } \\
\text { - sigo reto } 100 \text { metros }\end{array}$ \\
\hline
\end{tabular}

Fonte: Elaborado pelo autor.

Questão 2: Descreva uma situação do seu dia a dia em que você tenha utiliza de algum tipo de "FUNÇÃO".

\section{Quadro 3. Comparativo Questão 2}

\begin{tabular}{|l|l|}
\hline Resposta dada no pré-teste & Resposta dada no pós-teste \\
\hline - minha função é estudar & - o preço do leite é função do numero de litros \\
- não sei & - quando vamos ao mercado, comprar coca-cola, \\
- a minha função é obedecer & - tomachas e outras coisas. \\
- quando quero mandar alguém & e tanto de açúcar \\
fazer algo: sua função é arrumar o & que colocar tanto de café \\
quarto. Ou ate mesmo falando da & - quando eu vou ao mercado comprar algo ou em \\
função de algum aparelho. & uma farmácia para comprar coisas, o preço que \\
- configurar alguns apps no meu & eu vou pagar é uma função do que eu compro \\
notebook. & - quando vou fazer trilha vai gasolina na moto \\
& - quando vamos no mercado comprar um litro de \\
\hline
\end{tabular}




\begin{tabular}{|l|l|}
\hline & $\begin{array}{l}\text { coca, vamos pagar um preço, mas se for dois } \\
\text { litros o valor aumentara e pagaremos pelos dois } \\
\text { produtos. }\end{array}$ \\
\hline
\end{tabular}

\section{Fonte: Elaborado pelo autor.}

Percebemos uma boa evolução na ideia do que é uma função, pois no questionário inicial nenhum aluno conseguiu remeter o conceito para o campo matemático.

Nas questões relacionadas ao pensamento computacional observou-se uma melhora significativa nas respostas. Inicialmente foram realizadas 8 questões sobre o pensamento computacional e posteriormente a aplicação das atividades propostas, foram escolhidas três questões relativamente mais difíceis do que as realizadas no teste inicial. Apesar disto, o índice de desempenho geral de acertos de $74 \%$ foi superior ao inicialmente apresentado. O emprego destas questões mais difíceis deu-se justamente com a intenção de verificar avanços na aprendizagem dos alunos. É importante dizer, que durante a realização do questionário final os estudantes não precisaram ser orientados sobre como deveriam responder as questões ou mesmo ajudá-los a interpretar, pois já conseguiam de forma autônoma interpretar e responder corretamente as perguntas propostas. $\mathrm{O}$ que não aconteceu no diagnostico inicial.

Como resultado da prova de conhecimentos específicos, em torno de $60 \%$ dos estudantes atingiu a média mínima referente às avaliações do estado onde a média é 6,0. Este resultado ainda deixa a desejar, porém, percebeu-se a evolução com relação à aprendizagem do conceito de funções, visto que no questionário diagnostico inicial, $90 \%$ dos estudantes não souberam responder as questões.

\section{Conclusões}

Embora seja desafiador trabalhar o pensamento computacional fazendo uso do computador, visto que na escola em que foi aplicado o projeto, as máquinas são velhas e praticamente sem manutenção, percebe-se por parte do educando um interesse bem relevante em estudar o tema.

O Scratch como ferramenta educacional quando apresentado aos estudantes despertou neles interesse, curiosidade e motivação pelo projeto, além de se sentir inseridos frente a novos desafios. O perfil dos estudantes é de pessoas que gastam parte do seu tempo todos os dias em frente a uma ferramenta tecnológica, e isso fez com que, ao precisar pensar com linguagens computacionais, se sentisse parte integrada do processo educacional e agente do próprio conhecimento, corroborando com os pressupostos da teoria de Papert.

Observou-se ainda que, durante a realização das atividades com o Scratch a turma mostrou-se dedicada e, apesar de ser uma turma com grandes limitações, percebemos uma evolução significativa na aprendizagem.

Precisamos olhar o educando na perspectiva de sujeito inserido na era digital, que possui acesso fácil a tecnologia, pois, sabendo que no Brasil, segundo o Instituto Brasileiro de Geografia e Estatística (IBGE) mais de $70 \%$ da população tem acesso à internet, precisamos melhorar nossas concepções de aprendizagens e unir modelos tradicionais de aprendizagens à modelos dinâmicos, possibilitando aos envolvidos no 
VIII Congresso Brasileiro de Informática na Educação (CBIE 2019)

Anais do XXV Workshop de Informática na Escola (WIE 2019)

âmbito escolar, uma melhora significativa na forma de concepção de sujeito inserido na sociedade atual.

\section{Referências}

Ausubel, D. P. (1982). A aprendizagem significativa: a teoria de David Ausubel. São Paulo: Moraes.

Martins, A. R. Q. (2012). Usando o Scratch para potencializar o pensamento criativo em crianças do ensino fundamental. $114 \mathrm{f}$. Dissertação de Mestrado - Programa de Pós-Graduação em Educação, Universidade de Passo Fundo, Passo Fundo, RS. Disponível em: http://www.upf.br/ppgedu/images/stories/defesa-dissertacao-amiltonrodrigo-de-quadros-martins.

Brackmann, Christian Puhlmann. (2017). Desenvolvimento do Pensamento Computacional Através de Atividades Desplugadas na Educação Básica. $226 \mathrm{f}$. Tese (Doutorado) - Informática na Educação, Cinted, Universidade Federal do Rio Grande do Sul, Porto Alegre, RS.

Brasil. Ministério da Educação. Base Nacional Comum Curricular. 2017. Disponível em: <http://basenacionalcomum.mec.gov.br/>. Acesso em: 29 mar. 2019.

Gonçalves, Antonio R. (2016). Matemática para cursos de graduação. São Paulo. Contexto e aplicações.

Miotto, P.; Cardoso, V.C. (2014). A Utilização do software Scratch para o ensino e a aprendizagem do conceito de função. Os desafios da Escola Pública Paranaense na Perspectiva do Professor, PDE, I.

Neto, Valter S.M. (2013). A utilização da ferramenta Scratch como auxílio na aprendizagem de lógica de programação. II Congresso Brasileiro de Informática na Educação (CBIE). Disponível em: http://www.brie.org/pub/index.php/wcbie/article/view/2675/2329.

Papert, S. (1980). Mindstorms: Children, Computers, And Powerful Ideas. Basic Books.

Pazinato, Ariane M.; Moreira, C.; Rizzon, E. C.; Mallmann, Maria E.; Oro, Neuza T.; Uczay, Thaíse. (2014). Scratch: instrumento para o aprendizado criativo na formação continuada de professores. $3^{\circ}$ Seminário Nacional de Inclusão digital. Passo Fundo, RS.

Román-González, M., Pérez, J. C., \& Carmen Jiménez-Fernández. Test de Pensamiento Computacional: diseño y psicometría general, Octubre 14-16, 2015, Madrid, ESPAÑA. III Congreso Internacional sobre Aprendizaje, Innovación y Competitividad (CINAIC 2015), 2015. https://doi.org/10.13140/RG.2.1.3056.5521

Smole, K.S.; Diniz, M. I.; Milani, E. (2007). Cadernos do Mathema: Jogos de Matemática do $6^{\circ}$ ao $9^{\circ}$ ano. Porto Alegre. Artmed. 